\title{
The analytic-synthetic distinction and the classical model of science: Kant, Bolzano and Frege
}

\author{
Willem R. de Jong
}

Received: 10 April 2007 / Revised: 24 July 2007 / Accepted: 1 April 2008 /

Published online: 8 November 2008

(C) The Author(s) 2008. This article is published with open access at Springerlink.com

\begin{abstract}
This paper concentrates on some aspects of the history of the analyticsynthetic distinction from Kant to Bolzano and Frege. This history evinces considerable continuity but also some important discontinuities. The analytic-synthetic distinction has to be seen in the first place in relation to a science, i.e. an ordered system of cognition. Looking especially to the place and role of logic it will be argued that Kant, Bolzano and Frege each developed the analytic-synthetic distinction within the same conception of scientific rationality, that is, within the Classical Model of Science: scientific knowledge as cognitio ex principiis. But as we will see, the way the distinction between analytic and synthetic judgments or propositions functions within this model turns out to differ considerably between them.
\end{abstract}

Keywords Analytic-synthetic $\cdot$ Science $\cdot$ Logic $\cdot$ Kant $\cdot$ Bolzano $\cdot$ Frege

\section{Introduction}

As is well known, the critical Kant is the first to apply the analytic-synthetic distinction to such things as judgments, sentences or propositions. For Kant this distinction is not only important in his repudiation of traditional, so-called dogmatic, metaphysics, but it is also crucial in his inquiry into (the possibility of) metaphysics as a rational science. Namely, this distinction should be "indispensable with regard to the critique of human understanding, and therefore deserves to be classical in it" (Kant 1783, p. 270).

Later on, Bolzano and Frege develop their own views on the analytic-synthetic distinction. Bolzano does so in his effort to develop a general theory of science. Frege

\footnotetext{
W. R. de Jong $(\bowtie)$

Faculteit der Wijsbegeerte, Vrije Universiteit Amsterdam, De Boelelaan 1105, 1081 HV Amsterdam, The Netherlands

e-mail: wr.de_jong@ph.vu.nl
} 
does so in the context of his logicism program. That is, roughly speaking, the reduction of arithmetic to logic. Both Bolzano and Frege deviate-be it in rather different ways-from the Kantian distinction between analytic and synthetic judgments, but each claims that his own view of this distinction, although a correction, is in the spirit of what Kant really meant by it. ${ }^{1}$

\section{The pre-critical Kant and the distinction between analytic and synthetic method}

The claim that Kant conceives of a genuine science according to the Classical Model of Science will not be substantiated extensively here. ${ }^{2}$ I refer only to a passage from the foreword to the second edition of the Kritik der reinen Vernunft where Kant praises Wolff's strict method in science:

In someday carrying out the plan that criticism prescribes, i.e., in the future system of metaphysics, we will have to follow the strict method of the famous Wolff, the greatest among all dogmatic philosophers, who gave us the first example ... of the way in which the secure course of a science is to be taken, through the regular ascertainment of the principles, the clear determination of concepts, the attempt at strictness in the proofs, and the prevention of audacious leaps in inferences. (Kant 1787, $B$ xxxvi)

When the critical Kant says that we have to follow 'the strict method of the famous Wolff', this may be a bit misleading. With these words he intended to say in the first place that Wolff in his various works has demonstrated very well how to conceive of a discipline as a proper science. But given this paradigm of scientific rationality, the pre-critical Kant already strongly disagrees with Wolff on the correct method of metaphysics.

Beth already argued convincingly that Kant's "theory of science, as set forth in his Kritik der reinen Vernunft, cannot be fully understood without reference to his earlier writings", especially his essay Untersuchung über die Deutlichkeit der Grundsätze der natürlichen Theologie und der Moral (1764). ${ }^{3}$ This essay focuses on a "comparison of the manner in which certainty is attained in mathematical cognition with the manner in which certainty is attained in philosophical cognition" (as the title of the "first reflection' has it) (Kant 1902, p. 283). Kant is contrasting here the method of mathematics and that of philosophy (or metaphysics) from the point of view of the Classical Model of Science. Moreover, referring to this essay he says in the announcement of his lectures for the winter semester 1765-1766:

\footnotetext{
1 Bolzano praises Kant as the one who first fully recognized the importance of the analytic-synthetic distinction. But he concludes in the end that the prevalent definitions of analyticity, like that of Kant, devote insufficient attention to "what makes this sort of judgment really important" (Bolzano 1837, §148, n. 4). And of course his own conception of analyticity purports to be an improvement. See for Frege (1884, pp. 3, 99-100).

2 See the introductory paper of this issue (de Jong and Betti (2008)) for a full structural exposition of this model of scientific explanation. See further for Kant as an adherent of this model: de Jong (1995a).

3 Beth (1965, p. 41).
} 
I have sought to show in a short and hastily composed work that this science [i.e. metaphysics] has, in spite of the great efforts of scholars, remained imperfect and uncertain because the method peculiar to it has been misunderstood. Its method is not synthetic, as that is of mathematics, but analytic [as that of Newtonian physics] (Kant 1902, p. 308). ${ }^{4}$

In early modern philosophy and science one very often finds a distinction between on the one hand analytic, or regressive and on the other hand synthetic, compositive or progressive method. This distinction has to be interpreted mainly directionally. Analysis serves here as a method (way or route) in the direction of the principles of a science; synthesis has just the opposite direction: it goes from the principles to what is grounded on them. As Leibniz put it: "Synthesis is achieved when we begin from principles and run through truths in good order... Analysis goes back to the principles" (Leibniz 1679 , p. 232). ${ }^{5}$ But the important point is that these notions do not regard only the ordering of propositions (according to the Proof Postulate (3) of the Classical Model of Science), but also that of concepts (according to the Composition Postulate (2b)). Synthesis is a movement from causes to effects or consequences, from the simple (the parts) towards the more complex (the whole) and from the more general to the more particular (individual). Analysis features precisely the opposite direction; it is a movement from the more particular (or specific) to the more universal, from the whole to its parts and from consequences or effects to their causes. And these terms are applied to the system of propositions as well as to the system of concepts of a science; one finds that in early modern philosophy these two orderings are often not clearly distinguished.

In Über die Deutlichkeit Kant sums up some differences between the manner in which certainty is attained in mathematics and in philosophy or metaphysics. These differences concern various aspects of a science. One of them is presented in terms of the analytic-synthetic distinction and has to do with definitions and thus with the Composition Postulate:

Mathematics arrives at all its definitions synthetically, whereas philosophy arrives at its definitions analytically (Kant 1902, II 276-280).

This distinction between analytic and synthetic definitions (cf. Kant 1902, II 277; IX 141) is the outcome of applying the distinction between analytic and synthetic method (in its directional sense) to the ways in which we can arrive at concepts:

Either by the arbitrary combination of concepts, or by separating out that cognition which has been rendered distinct [deutlich] by means of analysis. Mathe-

\footnotetext{
4 Kant, claiming that Wolff does the same, supposes that mathematics only needs synthetic method. See for the reference to Newtonian physics added by me: "The true method of metaphysics is basically the same as that introduced by Newton into natural science and which has been of such benefit to it" (Kant 1902, II 286 ; cf. 275, 283, 71). Kant's claim is more precisely that metaphysics, like physics but unlike mathematics, has to use analytic method before it can use synthetic method.

5 Cf. also (Kant 1902, IX 149): "Analytic is opposed to synthetic method. The former begins with the conditioned and grounded and proceeds to principles (a principiatis ad principia), while the latter goes from principles to consequences [cf. the propositional coherence! WRdJ] or from the simple to the composite [cf. the conceptual coherence; WrDJ]".
} 
matics only ever draws up its definitions in the first way. ... [there] the definition obviously comes into being as a result of synthesis.

The situation is entirely different in the case of philosophical definitions. In philosophy, the concept of a thing is always given, albeit confusedly [verworren] or in an insufficiently determinate fashion. The concept has to be analysed; ...

It is the business of philosophy to analyse concepts which are given in a confused fashion, and to render them complete [ausführlich] and determinate. The business of mathematics, however, is that of combining and comparing given concepts of magnitudes, which are clear [klar] and certain, with a view to establishing what can be inferred from them (Kant 1902, II 276-278).

In philosophy the concept of a thing is given, in mathematics it is made. It is clear that when Kant connects the distinction between made and given concepts with the opposition analytic-synthetic, these last terms are taken in their directional sense. Indeed, "to make a distinct concept is the synthetic method, to make a concept distinct is the analytic one" (Kant 1902, XXIV 844).

This view of the clarification or definition of concepts by analysis - needed to make a concept distinct (deutlich) in those cases where it is confused (verworren) - is the paradigm for Kant's analytical judgments in his critical period. Note that this analysis (which has the direction of analytical method) concerns only concepts. It is an analysis notionum. As such it has little to do with the Proof Postulate, i.e. the way propositions are demonstrated or proved from first principles.

\section{The critical kant and the possibility of metaphysics as an a priori science}

In the first Kritik Kant resumes his ideas concerning the difference between philosophical and mathematical method of Über die Deutlichkeit (cf. Kant 1787, A 712-739/B 741-767). But in that work he also presents for the first time the distinction between analytic and synthetic judgments. This distinction is also found in a preamble of the Prolegomena (1783), written by Kant as an accessible synopsis of the first Kritik. It opens with a general remark regarding the domain of any science:

If one wishes to present a body of cognition as science, then one must first be able to determine precisely the differentia it has in common with no other science, and which is therefore its distinguishing feature; otherwise the boundaries of all the sciences run together, and none of them can be dealt with thoroughly according to its own nature.

Whether this distinguishing feature consists in a difference of the object or the source of cognition, or even of the type of cognition, or several if not all of these together, the idea of the possible science and its territory depends first of all upon it (Kant 1783, p. 265).

This passage reflects in the first place the Domain Postulate of the Classical Model of Science (cf. de Jong and Betti (2008)). But in the present context the introduction 
of a difference between source of cognition (Erkenntnisquelle) on the one side and type of cognition (Erkenntnisart) on the other side is more relevant.

Speaking of sources of knowledge, as we shall say henceforth, refers to a primarily epistemological difference of ways in which a proposition can be known. And this rather dynamical approach results in a distinction of two kinds of propositions or judgments. According to Kant there are two different sources of knowledge. Knowledge is a priori if it has its source (only) in reason; knowledge is a posteriori if its source is (also) empirical. This distinction is related to Leibniz's difference between truths of reason and truths of fact and Hume's contrast between relations of ideas and matters of fact.

Kant states very clearly that the source of metaphysical knowledge should not be empirical but a priori. "Metaphysical cognition must contain nothing but judgments $a$ priori" (Kant 1783, p. 266). Metaphysics has to be a (pure) rational or a priori science. If metaphysics as a science is possible one has to show at least that its principlesfundamental propositions as well as concepts—are a priori.

Apart from sources of knowledge there are also types of knowledge. The latter should be a distinction concerning the 'content' of judgments or propositions. In the next section we will elaborate somewhat more on this. For the moment it is enough to observe that Kant distinguishes two types of cognition, which are labelled by him as analytic and synthetic judgements respectively. The analytic-synthetic distinction is used principally to introduce a contrast between two types of judgments within metaphysics:

Properly metaphysical judgments are one and all synthetic. Judgments belonging to metaphysics must be distinguished from properly metaphysical judgments. Very many among the former are analytic, but they merely provide the means to metaphysical judgments, to which the aim of the science is completely directed, and which are always synthetic. For if concepts belong to metaphysics, e.g., that of substance, then necessarily the judgments arising from their mere analysis belong to metaphysics as well, c.q., substance is that which exists only as subject, etc., and through several such analytic judgments we try to approach the definition of those concepts (Kant 1783, p. 273).

Metaphysics, if possible, has to be a rational science, like mathematics and pure physics. The propositions of such a science have to be a priori; that is necessary and strictly universal. The critical Kant sees a rational science in the first place as a system of synthetic propositions. Analytic propositions regard only its concepts; and even then only insofar as these concepts are in need of clarification. According to Kant, this should be especially the case for the concepts of metaphysics. In mathematics analytic propositions hardly have any role, simply because mathematical concepts-which are always introduced by construction-are as such already distinct.

Concerning sources of knowledge one has to distinguish between the justification of a proposition and its origin. A judgment is a priori if it is (or can be) justified by a priori sources of knowledge alone. But pure a priori knowledge has to be not only justified a priori, but the concepts or representations (as the case may be) involved in it need to be a priori too. All metaphysical judgments have to be pure a priori judgments. 
As we saw Kant does not relate the analytic-synthetic distinction to sources of knowledge but to what is called types of cognition. And although it is stated that this distinction has not 'much utility' outside metaphysics, the application of this distinction is not restricted to a priori sciences like mathematics, (pure) physics or metaphysics. Analytic judgments can concern the clarification of a priori as well as empirical concepts. And thus the judgment that gold is yellow, in which according to Kant the empirical concept of gold is clarified, is also presented as an example of an analytic judgment (cf. Kant 1783, p. 267). Moreover, in Kant all judgments $a$ posteriori are synthetic judgments.

\section{Kant on analytic and synthetic judgments}

But let us look somewhat more precisely at the way Kant introduces the distinction between analytic and synthetic judgments. He does so in both introductions to the first Kritik and, as already noted, in the preamble of the Prolegomena. Here are four important passages:

A Analytic judgements are "merely explicative [Erläuterungsurteile] and add nothing to the content of the cognition"; synthetic judgments are "ampliative [Erweiterungsurteile] and augment the given cognition" (Kant 1783, p. 266). ${ }^{6}$

B In the first Kritik the distinction between analytic and synthetic judgments is characterized as follows: In all [affirmative subject-predicate judgments] ..., this relation is possible in two ways. Either the predicate $B$ belongs to the subject $A$ as something that is (covertly [versteckterweise]) contained in [enthalten in] this concept $A$; or $B$ lies entirely outside the concept $A$, though to be sure it stands in connection with it. In the first case I call the judgment analytic, in the second synthetic (Kant 1787, A 6-7/B 10). ${ }^{7}$

In the opening of the Prolegomena Kant also presents a principle of analytic judgments:

C "All analytic judgments rest entirely on the principle of contradiction and are by their nature a priori cognitions". Synthetic judgments "can by no means arise solely from the principle of analysis, namely the principle of contradiction; they demand yet a completely different principle" (Kant 1783, p. 267). ${ }^{8}$

This principle of synthetic judgments is formulated in Über eine Entdeckung (1790) as follows:

D Synthetic judgments "are not possible save under the condition of an intuition (Anschauung) underlying the concept of their subject, which, if they are judgments of experience, is empirical, and if they are synthetic judgments a priori, is pure intuition a priori" (Kant 1902, VIII 241). ${ }^{9}$

\footnotetext{
6 Cf. Kant (1787, A 7/B 11), Kant (1902, VIII 228).

7 Cf. Kant (1783, p. 266), Kant (1902, VIII 228, 232).

8 Cf. Kant (1787, A 151/B 190-191), Kant (1902, XX 323).

9 Cf. Kant (1787, A 158/B 197).
} 
To understand what is going on in these passages it may be helpful to have first a brief look at notions like cognition, judgment, concept and intuition.

In the second edition of the Kritik Kant indicates that he has never been satisfied by the way logicians explain judgments, namely as "the representation [Vorstellung] of a relation between two concepts". First of all this explanation only fits categorical judgments (or, as we shall say here, usually: $S$ (ubject) $-P$ (redicate)-judgments), but not hypothetical or disjunctive judgments. But furthermore, and more importantly, in this explanation it is in no way indicated "wherein this relation consists". In an (affirmative) $S-P$-judgment the predicate-concept is related to the subject-concept by the copula is. According to Kant the aim of the copula is "to bring given cognitions to the objective unity of apperception". In other words, the copula has to be "a relation that is objectively valid"; in judgments, representations are related by relating them to an object (Kant 1787, B 137, 140-142).

Concepts and intuitions are cognitions (Erkenntnisse), that is, representations which are not only perceptions (representations with consciousness) but also objective, that is, related to an object. An intuition "is immediately related to the object and is singular, [a concept] is mediate [i.e. related to the object mediately], by means of a mark [Merkmal], which may be common to several things" (Kant 1787, A 320/B 377). ${ }^{10}$ Judgments are also cognitions, and thus are objective too:

Since no representation pertains to the object immediately except intuition alone, a concept is thus never immediately related to an object, but is always related to some other representation of it (whether that be an intuition or itself already a concept). Judgment is therefore the mediate representation of an object, hence the representation of a representation of it (Kant 1787, $A$ 68/B 93).

In a $S$ - $P$-judgment the predicate forms a mediate representation of the way its object is represented by (the concept of) the subject. Or again in the words of Kant (but focussed on synthetic judgments): "It is clear ... that in synthetic judgments I must have in addition to the concept of the subject something else $(X)$ on which the understanding depends in cognizing a predicate that does not lie in that concept as nevertheless belonging to it" (Kant $1787, A$ 8). ${ }^{11}$ Logically this all seems to imply that $S-P$-judgments are conceived of according to a version of what may be called the attribution theory of the copula:

(K1) An (affirmative) $S$ - $P$-proposition says that the object(s) represented by (the concept of) the subject is (are) also represented (mediately) by the predicateconcept. $^{12}$

10 Cf. Kant (1787, A 239/B 298). See also B 137: "Understanding is, generally speaking, the faculty of cognitions. These consist in the determinate relation of given representations to an object. An object, however, is that in the concept of which the manifold of given intuition is united". Note that the last part of this statement reflects the core of Kant's theory of transcendental idealism.

11 Cf. Kant (1902, XVII 278, 344-345, 616-617, 653-654; XVI 671; IX 111).

12 From a semantic point of view the various conceptions of the copula can be classified globally as follows:

1-Extensional theories: An $S-P$-proposition says there is a relation between objects signified by the subject ' $S$ ' and objects signified by the predicate ' $P$ '. 
But let us return to the quoted passages on the analytic-synthetic distinction. Observing that Kant applies this distinction naturally to judgments that are true, one can discern a cognitive from a logical aspect in this distinction.

The difference between Erweiterungsurteile and Erläuterungsurteile (cf. A) does pertain to the cognitive aspect of the distinction between analytic and synthetic judgments. But note that Kant is not saying that analytic judgments have no cognitive content or are cognitively empty; he is saying that they do not augment the content of the cognition. And that is something else. An analytic judgment is a judgment in which a (confused) concept is made distinct by explicating one of its marks as a predicate: "Analytic judgments say nothing in the predicate except what was actually thought in the concept of the subject, though not so clearly nor with the same consciousness" (Kant 1783, p. 266). In contrast, in a synthetic $S-P$-judgment the concept $P$ extends the cognition (of the object) with respect to that of (the concept of) $S$.

Passage B affords-I think-Kant's best characterization of the distinction between analytic and synthetic judgments. To begin with, the word 'versteckterweise' (although only in brackets) refers to the cognitive requirement of analytic judgments. But this requirement is obviously based on a relation between the concept of the subject and the predicate in an (affirmative) judgment; more specifically, on the relation of containment. From a logical point of view Kant's analytic judgments require an intensional analysis of $S-P$-propositions (that is: an analysis of judgments as a relation of concepts). It can be characterised for affirmative judgments as follows:

(K2) a If a judgment $S$ is $P$ is analytic, then the predicate-concept $P$ is contained in (ist enthalten in) the subject-concept $S$, i.e., $E I(P, S)$.

b $\quad E I(P, S)$ iff the concept $S$ can be analyzed as a conjunction of concepts (Merkmale) with the concept $P$ as one of its conjuncts, i.e. ${ }^{13}$

$$
\exists X_{1} \exists X_{2} \ldots \exists X_{n}\left(S=X_{1} \oplus X_{2} \ldots \oplus X_{n} \oplus P\right) .
$$

Let us call this the logical requirement of analyticity. ${ }^{14}$ The cognitive requirement together with this logical requirement, determine a fair characterization of Kant's notion of analyticity as applied to $S-P$-judgments. Henceforth this characterization will be referred to as analyticity .

The principle for analytic ${ }_{\mathrm{K}}$ judgments (cf. C) as introduced by Kant concerns the justification of those judgments; i.e. the ordo cognoscendi. Provability according to

\footnotetext{
Footnote 12 continued

2-Attribution theories: An $S-P$-proposition says there is a relation between objects signified by ' $S$ ' and the attribute (concept) signified by ' $P$ '.

3-Intensional theories: An $S-P$-proposition says there is a relation between attributes (the concept) signified by ' $S$ ' and the attribute (concept) signified by ' $P$ '.

13 This is an improved version of my characterization of Kant's analyticity in: de Jong (1995b, p. 628). Note that an intensional analysis of $S-P$-propositions does not rule out an interpretation of the copula according to the attribution theory. Or in the words of Kant, focussing on the principle of analyticity: "The principle of identity and contradiction contains the comparison of two predicates $a$ and $b$ with $x$, but only in such a way that the concept $a$ of $x$ is compared with $b .$. , thus the $x$ is idle" (Kant 1902, XVII 653-654).

14 Kant sometimes characterizes his logical requirement of analyticity also in terms of (partial) identity of the two concepts involved in a $S-P$-judgment. Cf. Kant (1787, A 7/B 10), Kant (1902, IX 111, XX 322).
} 
the principle of contradiction $(P C)$ is a (necessary) condition for analytic ${ }_{\mathrm{K}}$ judgments (cf. Kant 1787, A 151/B190). This condition is at the same time sufficient to show that analytic propositions are a priori (necessarily true).

Frege states that Kant underestimated the value of analytic judgments by defining them too narrowly. He offers two reasons.

(i) First, Kant restricts analyticity wrongly to subject-predicate judgments.

Although Kant, as we saw, acknowledges that there are also other sorts of judgments, Frege is right. Kant's explication of analyticity is restricted to affirmative $S-P$-judgments, though he observes that "the application to negative ones is easy" (Kant 1787, A 6/B 10). However, it remains unclear how the analytic $_{\mathrm{K}}$-synthetic $\mathrm{K}$ distinction can be applied for instance to hypothetical or disjunctive judgments. $s$

(ii) In the second place Kant analyses complex concepts as a conjunction of partial concepts (cf. b). As Frege has it: "Kant seems to think of concepts as defined by giving a simple list of characteristics in no special order". This means that Kant adheres to the Postulate of Classical Definition. ${ }^{15}$ And Frege very justly claims that there are various other forms of conceptual complexity. Bolzano made similar remarks. Kant's speaking of 'containment' is "a merely figurative form of expression" which, so Bolzano says with some understatement, falls "somewhat short of logical precision" (Bolzano 1837, §148n).

The passages A and B indicate that synthetic judgments are judgments which "augment the given cognition" and so do not satisfy the logical requirement of analyticity . Restricted to $S-P$-judgments the 'ampliative' character of synthetic judgments obviously has to be conceived in roughly the following manner:

(K3) In a synthetic $S-P$-judgment the cognition of the object 'given' by (the concept of) the subject $S$ is extended by the predicate-concept $P$.

This is the cognitive requirement of Kant's synthetic judgments. An $S$ - $P$-judgment that satisfies this requirement and does not satisfy the logical requirement of analyticity (reading Kant's " $B$ lies entirely outside the concept $A$ " as $\neg E I(B, A)$ ) will be called here a synthetic ${ }_{\mathrm{K}}$ judgment. Of course, synthetic ${ }_{\mathrm{K}}$ judgments do not satisfy the cognitive requirement of analyticity. Synthetic $\mathrm{K}_{\mathrm{K}}$ judgments are not analytic $\mathrm{K}_{\mathrm{K}}$. And also the other way around: analytic ${ }_{\mathrm{K}}$ judgments are not synthetic $\mathrm{K}_{\mathrm{K}}$.

Not much need be said here of the principle of synthetic $\mathrm{K}_{\mathrm{K}}$ judgments (cf. D). This principle is obviously based on the logical analysis of $S-P$-judgments according to the attribution theory of the copula (see n. 12). Moreover it refers to intuition because knowledge has to be knowledge of (in some sense possible) objects and objects cannot be represented to us except by or via intuition. For apart from concepts, only intuitions represent their object immediately. However, contrary to the principle of analyticity, the principle of synthetic judgments does not state a condition for syntheticity, but only a condition for the possibility of synthetic judgments. The principle also includes a condition to discriminate between synthetic judgments a posteriori and synthetic judgments a priori. In the former the object has to be represented by empirical intuition or intuition a posteriori, in the latter by intuition a priori. As far as judgments

15 Frege (1879, p. 100). Cf. de Jong and Betti (2008). 
a priori are concerned this principle seems to be taken from the way Kant thinks mathematicians prove their theorems, namely by intuition a priori.

Analytic $_{\mathrm{K}}$ and synthetic $\mathrm{K}_{\mathrm{K}}$ judgments exclude one another. But Kant also suggests sometimes that any $S-P$-judgment should be either analytic or synthetic. ${ }^{16}$ Most interpreters seem to ascribe this view to Kant in practice. And in so far as the analytic-synthetic distinction is conceived only according to its logical aspects, this would indeed be correct. However, as we saw, for Kant there is a cognitive condition operative in this distinction as well.

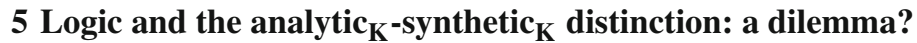

In his Kant and the Foundations of Analytical Philosophy Hanna starts his treatment of "Kant's cognitivist theory of analyticity" "by simply listing some of the propositions said by Kant to be analytic" (Hanna 2001, pp. 125-126). On this list of nine items we find examples as that all bodies are extended, that gold is a yellow metal and that every body is divisible. The analyticity of these propositions or judgments can easily be understood in terms of analyticity $_{K}$. But on Hanna's list are also the following, in this respect, rather problematic examples:

(1) Man is man.

(2) $a=a$, the whole is equal to itself.

(3) $a+b>a$, i.e. the whole is greater than its part.

(4) No predicate attaches to a thing that contradicts [that predicate]. ${ }^{17}$

Let us look more precisely at these 'examples' of analytic judgments.

Example (1) is from Immanuel Kant's Logik. Ein Handbuch zu Vorlesungen (1805). This work was not written by Kant but was composed by Gottlob Jäsche basing himself, as he claims at least, on Kant's handwritten notes to Meier's Auszug aus der Vernunftlehre. This latter work was used by Kant for some forty years as a manual for his lectures on logic. However, notwithstanding the claim of Jäsche, many have serious reservations about the Jäsche Logik (as we will call Kant's Logik henceforth) being a work by Kant himself (cf. Boswell 1988). This is also shown by the passage referred to here.

The proposition 'Man is man' is indeed presented in the Jäsche Logik as an example of an analytic judgment. It appears in a comment on a short section on tautological propositions (tautologische Sätze). This section reads as follows:

The identity of the concepts in analytic judgments can be either explicit (explicita) or not-explicit (implicita). In the first case the analytical propositions are tautological (Kant 1902, IX 111).

In a comment it is stated also:

\footnotetext{
16 Cf. Kant (1787, A 6-7/B10), Kant (1783, p. 266).

17 Cf. Kant (1902, IX 111), Kant (1787, B 17, A 151/B 190).
} 
Propositions that are identical implicite, ..., are not empty of consequences or fruitless, for they make clear the predicate that lay undeveloped (implicite) in the concept of the subject through development (explicatio) (ibid.).

It is obvious that the notion of an analytic ${ }_{\mathrm{K}}$ judgment only fits what is labelled in the Jäsche Logik as an implicit analytical proposition (or judgment). In line with this Kant presents (1) in his own notes on logic as an example of Meier's explicit identical propositions, but it is there nowhere called analytic (cf. Kant 1902, XVI 667-674). And elsewhere Kant himself is even very explicit that tautological or (explicit) identical judgments are not analytic:

Analytical judgments are indeed founded upon identity, and can be resolved in it, but they are not identical, for they need to be dissected and thereby serve to elucidate the concept; whereas by identical judgments, on the other hand, idem per idem, nothing whatever would be elucidated (Kant 1902, XX 322). ${ }^{18}$

It can be concluded, pace Hanna, that tautological propositions like (1) are simply not analytic ${ }_{K}$ according to Kant. Tautological propositions do not satisfy the cognitive requirement which gives analytic propositions the character of Erlaüterungsurteile.

However, Hanna's examples (2) and (3) are surely said to be analytic by Kant. To substantiate his claim that "synthetic a priori judgments are contained as principles in all theoretical sciences of reason" he looks at (pure) mathematics and states that "mathematical judgments are all synthetic" (Kant 1787, A10/B 14). This implies among others that the principles of geometry have to be synthetic. And indeed, for instance, the axiom that the shortest line between two points is a straight line is classified as synthetic (and a priori). Nevertheless according to Kant:

a few principles that the geometers presuppose [voraussetzen] are actually analytic and rest on the principle of contradiction; but they also only serve, as identical propositions [identische Sätze], for the chain of method and not as principles, e.g., $a=a$, the whole is equal to itself, or $a+b>a$, i.e., the whole is greater than its part. And yet even these, although they are valid in accordance with mere concepts, are admitted in mathematics only because they can be exhibited in intuition (Kant 1787, B 16-17). ${ }^{19}$

Now, first we have to note that these examples of analytic judgments are traditionally conceived as common principles of geometry. 'The whole is greater than its part' (3) is Aristotle's favourite example of a common principle. It is also presented by Euclid in The Elements as a 'common notion' (as common principles are called by him). ${ }^{20}$ Principles such as (2) and (3) are not proper principles of geometry; they are

18 Cf. Kant (1902, XXIV 667): "Propositions which explain idem per idem advance cognition neither analytically, nor synthetically. By them I have neither an increase in distinctness, nor a growth in cognition". See also Kant (1902, XXIV 581, 767, 937).

19 Cf. Kant (1783, p. 269).

20 Cf. de Jong and Betti (2008). Euclid (I 155, 117-124). Note that Kant classifies some of the other common principles of Euclid as analytic too (Kant 1787, A 164/B 204-205). 
not 'axioms in the proper sense'. As principles that can be used in various sciences these principles have-for Kant, like tradition—only an instrumental role in proving geometrical theorems.

But why should principles as (2) or (3) be analytic? Well, according to Kant they are conceptual truths and rest on the $P C$, i.e. meet the principle of analytic judgments. But, first, do they really satisfy the logical requirement of analyticity ${ }_{K}$ ? Kant seems to think so. But as we conceive these propositions nowadays, they are not even $S-P$-propositions. They are relational, and surely (3) cannot be analysed adequately in terms of the relation EI. And secondly, do these principles satisfy the cognitive requirement of analyticity ${ }_{K}$ ? One can hardly say that in (2) a concept is clarified. And indeed these principles are presented by Kant as identical propositions or at least as functioning like identical propositions (note that for Kant identity includes partial identity). Hence accordingly these common principles of geometry do not meet the cognitive requirement of analyticity ${ }_{K} \cdot{ }^{21}$ In sum, it is rather dubious why (2) and (3) are analytic according to Kant's own standards.

Or should Kant, under influence perhaps of what he suggests here and there about any $S-P$-judgment needing to be either analytic or synthetic, have restricted his notion of analyticity here to the logical requirement of analyticity? However, be that as it may, one has to observe that in other respects, Kant always holds consistently and strictly to the cognitive requirement of the analytic-synthetic distinction in mathematics. For, he never applies the distinction between analytic and synthetic judgments to definitions in mathematics, i.e. to synthetic definitions as the pre-critical Kant already dubbed them. These definitions do not extend cognition or clarify a concept; they introduce or construct a concept by representing it in intuition a priori (cf. Kant 1787, $A$ 730/B 758, A 713/B 741).

The foregoing produced the impression that Kant conceives the proper principles (axioms) of mathematics as synthetic propositions while classifying common principles, although on rather dubious grounds, as analytic. But this would be somewhat too rash a conclusion. The situation in Kant is more complicated. Although Euclid does not mention them in his list of common notions (of equality and inequality), logical principles - and especially the principle of contradiction - are usually also seen as common principles of special sciences like geometry or physics. Aristotle is already very explicit on this. This brings us to the last 'example' of analytic propositions taken from Hanna.

Perhaps surprisingly, (4) is simply not called analytic by Kant. This proposition, saying that no predicate attaches to a thing that contradicts that predicate, is nothing other than the principle of contradiction. This principle is introduced here, to be sure, as the 'principle of all analytic cognition', but not as being itself analytic (cf. Kant 1787, A 150-153/B 189-193). Moreover, pace the prevalent interpretations of Kant's analyticity - supposing naturally that according to Kant logical propositions are

\footnotetext{
21 One of the other examples of analytical judgments listed by Hanna is 'No unlearned man is learned' (Hanna 2001, p. 126). This affirmative $S-P$-judgment with a negative concept being a part of the subjectconcept has a very tautological look about it. Nevertheless, again Kant says it is analytic.
} 
analytic $^{22}$ - nowhere in his published works have I found that he states that the $P C$ itself is analytic. Nor does he say that this principle is synthetic.

In any case, Kant has always been very reticent about the status of logic in connection to the analytic-synthetic distinction. This is not so strange. The way in which this distinction is introduced seems to lead to serious difficulties for logic (and-I thinkalso for Kant's metaphysics, but that is another question). The situation is grosso modo as follows:

I Theoretical (a priori) sciences as mathematics and pure physics are based on principles which are synthetic and a priori (cf. Kant 1787, $B$ 14).

II Analytic propositions are based on the principle of contradiction alone.

III The principle of contradiction is a first principle of logic.

To begin: assume that logic is an a priori science. For Bolzano and Frege at least this was no issue. And neither is it for Kant. ${ }^{23}$ Next, assume also with Kant and his contemporaries that the principle of contradiction $(P C)$ is a first principle of logic. Well, then one can ask the following simple question: Are the central propositions of logic analytic or synthetic a priori? However, this question creates something like a destructive dilemma:

First. According to (I), one has to stipulate that the propositions of logic are synthetic. Logic and especially its principles have to be synthetic a priori. And, as we will see, this is Bolzano's position in his Wissenschafslehre. But, next, one has to make clear how it is possible that precisely analytic ${ }_{\mathrm{K}}$ judgments should be based on the principle of contradiction alone (II). For whatever has to be demonstrated from a synthetic principle is according to Kant synthetic too.

Second. Observing that for Kant the $P C$ functions as the principle of analytic judgments (II), it is quite natural to assume that this principle itself is analytic too. For Kant stresses that proving the aprioricity of an analytical judgment involves only this logical principle (III). However, this move seems to violate (I) directly! And this is unacceptable, at least for Kant. Nevertheless, this is precisely what most of Kant's successors did. Among them are Frege, and subsequently twentieth century logical positivism and analytical philosophy.

However, for Kant this dilemma obviously does not arise. Although he conceives of (pure general) logic as an a priori science, he does not apply the analytic-synthetic distinction to it. How is this to be understood?

Well, to begin, there is some ambiguity in the phrase 'based on'. Criticizing his predecessors (like Hume or Leibniz) for not noticing that the propositions of mathematics are synthetic and not analytic, Kant distinguishes between inferences from a principle (erfolgen aus, erkannt werden können aus; folgern aus) and inferences according to a principle (folgen nach; erkannt können werden nach, erkennen nach). ${ }^{24}$

\footnotetext{
22 This includes Hanna's reading of Kant. Cf. Hanna (2001, pp. 140, 146-147). Bolzano and Frege, in conformity with the standard interpretation, also think that for Kant logic should be taken to be analytic. See for Bolzano: "As regards logic, Kant claims that it [that is, pure general logic] consists of nothing but analytic propositions, and thus needs no intuitions for its cognitions" (Bolzano 1837, Sect. 315; my translation).

23 Cf. Kant (1787, B vii, A 52/B 76, A54-55/B 78-79), Kant (1902, IX 13).

24 Cf. Kant (1787, B 14), Kant (1783, p. 268).
} 
Mathematical judgments should always be inferred in accordance with the $P C$, but they are not inferred from this principle. These judgments are synthetic because they can be inferred or deduced from the proper principles (or axioms) of mathematics which are synthetic as such. At the same time all (apodeictic) demonstration within a science has to proceed in accordance with the $P C$. In other words, this principle functions as a common (even ultimate) principle through which demonstration proceeds. The $P C$ is a principle of demonstration. However, for Kant this principle functions not only as a principle of demonstration but also, and even primarily, as a (common) principle of judgment (cf. Kant 1902, XXIV 88, 773). More specifically (and restricted to its positive use) one has to think here of the principle of analytic judgments: The truth of an analytic judgment can always be inferred or cognized 'in accordance with' the $P C$ (Kant 1787, A 151/B 190).

But what then is the status of logic? Kant characterizes logic, or more precisely pure general logic, as "the science of the rules of understanding in general" (Kant $1787, A 51 / B$ 76). And this means for him that logic is a canon and not an organon; i.e. logic is not a science that extends our cognitions. By a canon he understands "the sum total of the a priori principles of the correct use of certain cognitive faculties in general" (Kant 1787, A 796/B 824). ${ }^{25}$ Moreover, the critical Kant also speaks about this pure general logic as 'formal logic'. For it "abstracts from all content of cognition (whether it be pure or empirical), and concerns itself merely with the form of thinking (of discursive cognition) in general" (Kant 1787, $A 131 / B$ 176). ${ }^{26}$

From the perspective of the Classical Model of Science it has to be concluded, I think, that (pure general) logic is a science for Kant, to be sure, but that it is for him in the end not a genuine science. Kant seems to conceive of logic not as a theoretical science, but as a practical science in the tradition of the ars conception of logic. For him logic is only concerned with the formal rules of understanding or thinking and does not afford (objective) cognition. It is not a system of cognitive truths or judgments as mathematics or (pure) natural science (cf. Kant 1787, B 20). The first principles of logic and the rules subordinated to these are formal rules for objective cognition, but don't constitute objective cognition themselves. And so for Kant, in the end the distinction between analytic and synthetic judgments does not apply to logic. As we will see Bolzano and Frege do apply the analytic-synthetic distinction to logic, moreover they conceive of logic as a science in the sense of the Classical Model of Science.

\section{Bolzano on the analytic-synthetic distinction}

Heinrich Scholz and others have noticed that Bolzano is strongly influenced by Aristotle's theory of science. ${ }^{27}$ Moreover, Bolzano maintains a strict distinction between

\footnotetext{
25 Cf. Kant (1787, A 53/B 77), Kant (1902, XXIV 792; IX 13).

26 Cf. Kant (1787, A 54/B 78, B ix, xxvi, n.). See also Kant (1902, XXIV, 693): "The content of a cognition is the object or the matter and is distinguished from the form. A universal logic must abstract from all objects of thought". Ibid. 695: "Logic does not suffice for an organon, it does not have objects"; cf. Kant (1902, XVI 43, 45; IX 13, 15). Kant's conception of logic is in line with the scholastic doctrine that logic is concerned with second intentions.

27 Cf. Scholz (1937, pp. 452-453), Berg (1962, pp. 161-162), Buhl (1961, pp. 57-64).
} 
the order of being and the order of knowing. His magnum opus, the Wissenschaftslehre, has five parts. The first two deal with the nature and structure of science at the level of the ordo essendi, while in the remaining parts the ordo cognoscendi is central. The latter then has to be taken rather broadly, namely as the way in which man can know, discover and describe reality scientifically. Such topics as the clarification of concepts and definitions are not treated in the first two parts of the Wissenschaftslehre, but in the latter parts.

Bolzano sees Kant's distinction between analytic and synthetic judgments a priori as of some concern too:

With his synthetic judgments a priori Kant was on the right track to the insight that "an object has innumerable properties [Beschaffenheiten] which can be deduced [ableiten] with necessity from the concept of the object itself, though we do not think them as components of the concept [as they are in analytic judgments]" (Bolzano 1837, §65, n. 8).

Bolzano's own notion of analyticity, putting aside Kant's cognitive requirement of analyticity, regards only the ordo essendi. It applies in the first place to propositions (conceived of as truth-bearers) and not to judgments. Nevertheless, Bolzano emphasizes that the distinction between analytic and synthetic truths is especially important for the presentation of a science (cf. Bolzano 1837, Sects. 197, 447). Analytic propositions simply have no role in a (rational) science strictly conceived, that is from the point of view of the ordo essendi:

In my opinion not even one proposition in logic, or in any other science, should be taken to be a merely analytic truth. For I look upon any merely analytic proposition as much too unimportant to be incorporated in any science as a proper proposition [eigenthümliche Lehre] of it. Who would want to replenish geometry, for example, with propositions like: an equilateral triangle is a triangle, or is an equilateral figure, etc.? (Bolzano 1837, Sect. 12; my translation).

Like Kant, Bolzano conceives of scientific propositions first and foremost as synthetic, and he too allocates a very restricted role to analytic propositions. But unlike Kant, he also applies this insight to logic.

Bolzano presents a highly personal and, in its application, at first glance rather incomprehensible characterization of the analytic-synthetic distinction:

But suppose there is just a single [this phrase should be read as: at least one (auch nur ein einziger); WRdJ] idea in it [i.e. a proposition] which can be arbitrarily varied without disturbing its truth or falsity, i.e. if all the propositions produced by substituting for this idea any other idea we please are either true altogether or false altogether, presupposing only that they have denotation [ Gegenständlichkeit]. ... I permit myself, then, to call propositions of this kind, borrowing an expression from Kant, analytic. All the rest, however, i.e. in which there is not a single idea that can be arbitrarily varied without affecting their truth or falsity, I call synthetic propositions (Bolzano 1837, Sect. 148).

I will try to make clear how this definition has to be understood. 
To begin, notice that Bolzano, in contrast to Kant, does not apply the analytic-synthetic distinction to true propositions only. Moreover he supposes that any proposition is either analytic or synthetic. But even with these qualifications, Bolzano seems far removed from Kant. Nevertheless, he praises Kant as the one who was the first to fully recognize the importance of this distinction. He also believed that after Kant it was seldom kept sharply in mind. But Kant himself is partly to blame for this. Kant's notion of analyticity has some shortcomings. First, not all component parts of a concept need to be necessary or essential attributes of that concept. And secondly, not all component parts of a proposition are concepts (in the sense used here). Obviously Bolzano's intent is to give a more correct characterization of Kant's analyticity which does justice to what he conceives as the real importance of this notion.

Simplifying Bolzano's treatment of analyticity somewhat, I shall restrict the presentation here to propositions that are true, i.e. to what Bolzano himself calls analytic and synthetic truths (Bolzano 1837, Sect. 197). With his definition, of course, Bolzano tried to resolve the noted difficulties in Kant's analyticity. He did so in an ingenious way by attaching analyticity to the variability of a proposition salva veritate with respect to one or more ideas contained in it. The notion of analytic truth can be reconstructed more precisely as follows:

(B1) A proposition $\alpha$ is an analytic ${ }_{B}$ truth $={ }_{\mathrm{df}}$ there is at least one idea (Vorstellung) $\beta$ such that $\alpha$ is universally valid with respect to $\beta$.

(B2) A proposition $\alpha$ is universally valid (allgemeingültig) with respect to the ideas $\beta_{1}, \beta_{2}, \ldots \beta_{n}(n \geq 1)={ }_{d f} \beta_{1}, \beta_{2}, \ldots \beta_{n}$ are parts of $\alpha$ and every proposition (which is denotative (i.e. has Gegenständlichkeit)) arising from $\alpha$ by arbitrary simultaneous variation of the ideas $\beta_{1}, \beta_{2}, \ldots \beta_{n}$ is true.

(B3) A proposition $\alpha$ is a $\operatorname{synthetic}_{B}$ truth $=\mathrm{df} \alpha$ is true and $\alpha$ is not an analytic ${ }_{B}$ truth.

A first question is of course: is a proposition that is analytic ${ }_{K}$ also analytic ${ }_{B}$ ? Well, let me present an example to illustrate what Bolzano really meant. Kant stated that the proposition 'gold is yellow' is analytic because the concept gold is supposedly composed of the concepts of metal and yellow (Kant 1783, p. 267). Using the notation introduced in the description of Kant's logical requirement of analyticity, ${ }^{28}$ this proposition can be analysed (intensionally) as follows:

$$
M \oplus P \text { is } P \quad(M-\text { metal; } P-\text { yellow })
$$

It is obvious that this proposition always remains true under variation of the ideas $M$ and $P$. And thus one has to conclude that it is analytic ${ }_{\mathrm{B}}$ true too. Moreover, the example also makes clear that any proposition which is analytic $\mathrm{K}_{\mathrm{K}}$ is also analytic $\mathrm{B}_{\mathrm{B}}$ true. Indeed, in this Bolzano links up with the Kantian notion of analyticity.

Bolzano's characterization of analyticity also substantiates his complaint that Kant introduced a too narrow conception of analyticity. It is rather easy to construct propositions which are analytic (true) according to Bolzano but not in the Kantian sense. A more or less trivial example might be:

28 Note that Bolzano himself analyses $S-P$-propositions in another way! 


$$
M \oplus P \text { is }(P \text { or } Q) \text {. }
$$

\section{Two senses of analyticity}

There is more to be said concerning Bolzano's notion of analyticity. In the foregoing, I spoke without much ado of the parts of a proposition. In Kant's analytic propositions those parts are always concepts that are parts of other concepts. For Bolzano, however, what we would call nowadays the logical constants of a proposition are also parts of a proposition. That is, in our examples (1) and (2), not only ' $M$ ', ' $P$ ' and ' $Q$ ' but also the copula 'is' and the conceptual conjunction ' $\oplus$ ' represent ideas (Vorstellungen). These latter ideas are logical ideas.

This distinction between logical ideas and non-logically ideas is of some importance. For within the class of analytic ${ }_{\mathrm{B}}$ propositions Bolzano distinguishes still a special type of analyticity. Some analytic propositions are "logically analytic or analytic in the narrower sense" (Bolzano 1837, Sect. 148):

(B4) A proposition $\alpha$ is a logically analytic ${ }_{\mathrm{B}}$ truth $=_{\mathrm{df}} \alpha$ is universally valid with respect to the ideas $\beta_{1}, \beta_{2}, \ldots \beta_{n}(n \geq 1)$ and all parts of $\alpha$ besides $\beta_{1}, \beta_{2}, \ldots \beta_{n}$ are logical ideas.

For assigning a truth-value to logically analytic $\mathrm{B}_{\mathrm{B}}$ propositions nothing is necessary

besides logical knowledge, because the concepts that make up the invariant parts of these propositions all belong to logic. But judging the truth or falsity of [non-logically analytic ${ }_{\mathrm{B}}$ ] propositions requires quite another kind of knowledge, because concepts alien to logic exert an influence in them (Bolzano 1837, Sect. 148).

Kant's analytic $_{K}$ judgments are logically-analytic ${ }_{B}$. But this raises a further question. Why did Bolzano not restrict his notion of analyticity to the class of logically analytic $_{\mathrm{B}}$ truths? Note that it is precisely the notion of analyticity 'in its broad sense' which would be important for the presentation of a science. What is the real reason why Bolzano introduces his general notion of analyticity? The question is intriguing; also because most interpreters - even if they look seriously at Bolzano's analyticity 'in the broad sense' - do no succeed in making much sense of it. I think that one has to understand the role of this broad notion of analyticity in relation to the Classical Model of Science. I offer here only some hints about how this has to be done. ${ }^{29}$

Bolzano gives as examples of non-logically analytic ${ }_{\mathrm{B}}$ truths:

The soul of Socrates is a simple substance; the angles of an equilateral triangle are together equal to two right angles; if $a^{2} / 2=b$, then $a= \pm \sqrt{ } 2 b$; etc. For in each of these propositions, there is an idea (Socrates, equilateral, 2) which we can interchange with any other without affecting the truth of the proposition (Bolzano 1837, Sect. 447; my translation).

And he comments on these propositions as follows:

29 See for some more details and references: de Jong (2001). 
from these examples one can already derive that not every analytic proposition expresses a truth, which is understood self-evidently in such a way that it is totally superfluous to teach it to someone; one understands rather that pure analytic propositions at times are also not only remarkable enough to earn a position in a textbook, but that they themselves impose on us the obligation to provide them with a proof of their truth. Indeed it cannot be denied that such analytic propositions, the truth of which is not directly evident, can easily be known as true if one has achieved first knowledge of some synthetic truth from which they follow. In this way the propositions mentioned follow easily from the next three synthetic ones: each soul is a simple substance; the angles of any triangle are together equal to two right angles; if $\mathrm{a}^{2} / \mathrm{c}=\mathrm{b}$, then $\mathrm{a}= \pm \sqrt{ } \mathrm{cb}$ (ibid.).

In this passage analytic ${ }_{B}$ truths are presented as consequences of synthetic ${ }_{B}$ truths. Joëlle Proust, be it in a rather loose way, already indicated that this insight is very important for the analytic-synthetic distinction in Bolzano (cf. Proust 1986, pp. 145153).

We saw that Bolzano defines analyticity ${ }_{B}$ in terms of universal validity. Moreover this later notion is based on the variation of one or more ideas which are parts of a proposition. This variation is also the basis and foundation of Bolzano's characterization of the relation of logical consequence as derivability (Ableitbarkeit). Omitting a lot of details, the upshot with respect to the role of the analytic-synthetic distinction within the Classical Model of Science can be summarized as follows:

(1) A science is a system of synthetic $_{B}$ (true) propositions ordered by the Proof Postulate. ${ }^{30}$

(2) Analytic ${ }_{\mathrm{B}}$ truths only have a role in the ordo cognoscendi, or in the presentation of a science (ordo docendi).

It is noted already that all judgments that are analytic ${ }_{K}$ are also (logically) analytic $\mathrm{B}_{\mathrm{B}}$ truths. But in the following Bolzano clearly deviates from Kant:

(3) Every analytic ${ }_{B}$ truth is derivable (ableitbar) from a synthetic ${ }_{B}$ truth.

To understand the role of (3) within a science, one has to look to the Universality Postulate (cf. de Jong and Betti (2008)). This postulate requires that the propositions forming the core of such a science should be maximally or strictly universal. Aristotle made some effort to make clear what this should mean. Well, for Bolzano it is clearly also an important issue. And he uses the analytic-synthetic distinction to handle this: Analytic $_{B}$ truths are not proper principles or theorems of a science (cf. 2). For example, the geometrical truth that the angles of an equilateral triangle are together equal to two right angles is not strictly universal. But this truth can be directly derived from the proposition that the angles of any triangle are together equal to two right angles. The latter proposition is strictly universal; and it is only such propositions which are accepted in Euclidean geometry as theorems that have to be demonstrated:

\footnotetext{
30 Bolzano was never able to define the notion of scientific demonstration (Abfolge) underlying the Proof Postulate of the Classical Model of Science in a satisfactory way. But he assumes that scientific demonstration has to be a form of derivability at least (cf. Bolzano 1837, Sects. 162, 200).
} 
(4) Analytic B $_{\mathrm{B}}$ truths, unlike synthetic $\mathrm{B}_{\mathrm{B}}$ truths, are not strictly universal (as required by the Universality Postulate).

In the opening of the Wissenschaftslehre Bolzano criticizes the Kantian view that logic cannot be an organon (Bolzano 1837, Sects. 4, 5). Logic as Wissenschaftslehre is the art (Kunst) of the sciences, but it is also a science. And restricted to what we nowadays would conceive of as logic, it is a system of truths as such (Wahrheiten überhaupt) that Bolzano treats mainly in the second part, entitled Elementarlehre, of his Wissenschaftslehre. In this sense logical truths can be conceived as truths of any object. And in conformity with (1), Bolzano claims that these truths of logic are synthetic $\mathrm{B}_{\mathrm{B}}$ propositions (cf. Bolzano 1837, Sects. 12, 315).

The domain of any special science is a proper subset of the universal domain, and the synthetic ${ }_{B}$ truths of logic make their appearance within (the presentation of) a special science as logically analytic $_{\mathrm{B}}$ truths:

(5) If an analytic ${ }_{B}$ truth is logically analytic ${ }_{B}$, it is derivable from a synthetic ${ }_{B}$ truth of logic.

(6) If an analytic $\mathrm{B}_{\mathrm{B}}$ truth is non-logically analytic ${ }_{B}$, it is derivable from a synthetic $\mathrm{B}_{\mathrm{B}}$ truth, not being a truth of logic.

We saw that Kant labeled the common principles of geometry concerning (in) equality on somewhat dubious grounds as analytic. Bolzano evades the dilemma connected to the role of common principles in Kant, by distinguishing between a common principle as such and the restricted way it is applied within the domain of the special science concerned:

(7) Proper principles as well as common principles are synthetic ${ }_{\mathrm{B}}$ truths; but a common principle is used within a specific science in the form of an analytic ${ }_{B}$ truth that is derivable from that principle.

In summary, for Bolzano the analytic-synthetic distinction has to distinguish the proper propositions of a science from propositions that have some role in its presentation, especially in demonstration, but are not constitutive for the science concerned. Proper propositions (proper principles and theorems) of a science have to be synthetic $\mathrm{B}_{\mathrm{B}}$ truths. Analyticity in its broad sense demarcates propositions that do not satisfy the Universality Postulate. Note that this whole approach of Bolzano is intrinsically connected to his formal concept of variation of ideas and derivability.

For Bolzano logic is, different than in Kant, a science according to the Classical Model of Science too. Within specific sciences logically analytic ${ }_{B}$ truths (analyticity in the narrower sense) reflect the use of logical truths in demonstration. These analytic $\mathrm{B}_{\mathrm{B}}$ truths are derivable from synthetic ${ }_{\mathrm{B}}$ truths of logic.

\section{Frege's program and analyticity ${ }_{F}$}

Frege conceives of the notion of analyticity within his program of the reduction of arithmetic to logic. In his Grundlagen der Arithmetik Frege opens with the way he conceives of analytic and synthetic propositions. Like Kant he does so both for a priori 
and a posteriori propositions alike. The context is that of a critical reflection on the way in which propositions are proved in mathematics:

The problem becomes, in fact, that of finding the proof of the proposition, and of following it up right back to the primitive truths. If in carrying out this process, we come only on general logical laws and on definitions, then the truth is an analytic one, bearing in mind that we must take account also of all propositions upon which the admissibility of any of the definitions depends. If, however, it is impossible to give the proof without making use of truths which are not of a general logical nature, but belong to the sphere of some special science, then the proposition is a synthetic one. For a truth to be a posteriori, it must be impossible to construct a proof of it without including an appeal to facts, i.e., to truths which cannot be proved and are not general, since they contain assertions about particular objects. But if, on the contrary, its proof can be derived exclusively from general laws, which themselves neither need nor admit of proof, then the truth is a priori (Frege 1884, p. 4).

Frege is obviously an adherent of the Classical Model of Science too. ${ }^{31}$ But while Kant presents (general) logic only as a canon of the rules of understanding as such, logic is for Frege an organon, a system of truths. He seems even to be the first to present logic as a formalized axiomatic theory. He did so already in his Begriffsschrift (1879). Moreover, in his Grundlagen Frege identifies analytic truths simply with logical truths.

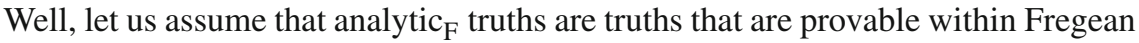
logic. Frege is very interested in the foundations of mathematics, especially in the relation between arithmetic and logic. He accepts Kant's thesis that geometrical truths are synthetic a priori judgments (cf. Frege 1884, pp. 101-102). But he denies that arithmetical truths are in the same box as geometrical ones, as Kant had argued. On the contrary, he seriously asks himself whether arithmetical truths are really different from logical truths:

The basis of arithmetic lies deeper, it seems, than that of any of the empirical sciences, and even than that of geometry. The truths of arithmetic govern all that is numerable. This is the widest domain of all; for to it belongs not only the actual, not only the intuitable (Anschauliche), but everything thinkable. Should not the laws of number, then, be connected very intimately with the laws of thought? (Frege 1884, p. 21).

This observation reflects the beginning of Frege's so-called logicistic program. And it is obvious that Frege introduced his own notion of analyticity especially in regard to this program. Against Kant, Frege intended to demonstrate that the a priori truths of arithmetic are not synthetic but analytic $\mathrm{F}$. As is well known, initially Frege claimed even to have done this. That is, he assumed to have shown

31 Frege (1893, p. vi). Cf. de Jong (1996). 
that the laws of arithmetic are analytic judgments and consequently a priori. Arithmetic thus becomes simply a development of logic, and every proposition of arithmetic a law of logic, albeit a derivative one (Frege 1884, p. 99).

To substantiate what such a reduction of arithmetic to logic requires, the Classical Model of Science is very helpful again. There are three conditions which have to be satisfied. They can be summarized as follows:

Arithmetic is reducible to logic iff

a The fundamental propositions of arithmetic are logically provable or logical truths.

b Any rule in the Proof Postulate of arithmetic is also a rule of logic (i.e. the methods of proof used in arithmetic are logically sound).

c The fundamental concepts of arithmetic are definable in terms of logical concepts.

The third condition is missed rather frequently by interpreters of Frege. Frege himself is partly to blame for this. For, he is not always very explicit on the need of this condition. Nevertheless the Grundlagen is mainly concerned to make plausible that arithmetical concepts can be defined in terms of logical concepts (cf. Frege 1884, p. 5). Yet also relevant here is the following: Missing this third condition allows one to ascribe to Frege the modern standard interpretation of analyticity with its distinction between formal (or logical) analytic and material analytic propositions. Or, to formulate it the other way around: From the point of view of the twentieth century semantic conception of analyticity, it can easily be missed that so-called material analytic propositions are usually simply not analytic ${ }_{F}$.

\section{Analyticity $_{F}$ and sources of knowledge}

In his Grundlagen Frege stresses that what is called here his logicist program has not only a mathematical but also a philosophical motivation. The latter requires that it be stated whether arithmetical truths are analytic, synthetic, a priori or even a posteriori (cf. Frege 1884, p. 3). This philosophical motivation turns out in the first place to be an epistemological one and it urged him to reconstruct the Kantian analytic-synthetic distinction in some way. Nevertheless in a footnote, Frege states that the way he conceives of the analytic-synthetic and the a priori-a posteriori distinctions does "not, of course, mean to assign a new sense to these terms, but only to state accurately what earlier writers, Kant in particular, have meant by them". But the passage to which this note is added reveals already at least one, rather important, difference between Kant and Frege:

Now these distinctions between a priori and a posteriori, synthetic and analytic, concern as I see it, not the content of the judgment but the justification for the making of the judgment (Frege 1884, p. 3).

As we saw, Kant relates the difference between a priori and a posteriori knowledge to sources of knowledge. But he conceives of the analytic-synthetic distinction in another way. The latter distinction regards two types of cognition (Erkenntnisarte) and should depend on what is called 'the content of cognition'. Roughly, one can 
say that in an analytic ${ }_{\mathrm{K}}$ judgment the predicate-concept is contained in the subjectconcept, and that in a synthetic $\mathrm{K}_{\mathrm{K}}$ judgment this is not so. Frege clearly deviates here from Kant. Moreover, assuming that the analytic-synthetic distinction as well as the $a$ priori-a posteriori distinction is concerned with the justification of judgments, these two distinctions land in the same box. "What I regard as a source of knowledge is what justifies the recognition of truth, the judgment" (Frege 1969, p. 286).

In an unpublished study Neuer Versuch der Grundlegung der Arithmetik (1924/25) the later Frege distinguishes three "sources of knowledge for mathematics and physics":

1. Sense Perception

2. The Geometrical Source of Knowledge

3. The Logical Source of Knowledge (Frege 1969, p. 299).

Each source corresponds to its own domain of knowledge. And this relates the distinction between sources of knowledge directly to the Domain Postulate of the Classical Model of Science. Not only in the Grundlagen but also elsewhere Frege harks back with striking frequency to this division of the sources or kinds of knowledge. ${ }^{32}$ This threefold division forms the first sketch of a theory of knowledge Frege never went on to elaborate. Yet it is of great importance for the precise interpretation of Frege's philosophy of mathematics (cf. Kitcher 1979).

The foregoing makes clear that Frege could break out of the dilemma described in Sect. 5 by replacing Kant's two-fold division of sources of knowledge with a threefold one. The consequence is that the analytic-synthetic distinction in Frege got a totally different place and role than in Kant (and in Bolzano too).

To begin, there is sense perception. Sense perception determines the domain of empirical knowledge or that of synthetic $_{\mathrm{F}}$ a posteriori judgments. It determines the domain of physics. Next there is the so-called 'geometrical source of knowledge'. This is the domain of intuition or as Kant should say: Anschauung a priori. Like Kant, Frege accepts geometrical truths as a priori and synthetic. The domain of synthetic ${ }_{\mathrm{F}}$ a priori propositions is the domain of geometry. Finally, there is what Frege calls 'the logical source of knowledge' which corresponds with the domain of logic or that of analytic $_{\mathrm{F}}$ judgments. ${ }^{33}$ Analytic $_{\mathrm{F}}$ judgments are as such also a priori.

For Frege a proposition is analytic $\mathrm{F}_{\mathrm{F}}$ if it can be proved from the laws of thought; such a logical proof "disregarding the particular characteristics of things, is based solely upon laws of which all knowledge rest" (Frege 1879, p. ix). The domain of logic is "the widest domain of all; for it belongs not only to the actual, not only to the intuitable, but everything thinkable" (Frege 1884, p. 21). Frege reconstructs the Kantian notion of analyticity rather drastically in such a way that an analytic ${ }_{\mathrm{F}}$ truth becomes nothing else than a truth of logic or a logical truth. A judgment is synthetic $\mathrm{F}_{\mathrm{F}}$ just in case it is not

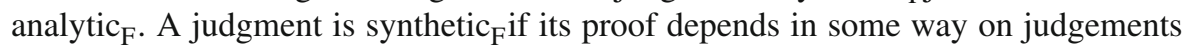
concerning particular characteristics of things, i.e. from judgment tied to a specific domain of knowledge, for instance that of geometry or that of physics.

32 Compare Frege (1884, pp. 20-21), Frege (1893, p. xv). See also Frege (1990, pp. 50, 103, 163).

33 Frege (1969, p. 299), cf. Frege (1884, p. 4). 
Frege connects the Kantian distinction between synthetic and analytic propositions in the first place with the question whether a judgment does or does not extend our knowledge. More precisely, he sees this distinction primarily in terms of Kant's cognitive requirement of synthetic judgments (i.e. as Erweiterungsurteile). Kant's analytic judgments are thereby interpreted as judgments that do not satisfy the cognitive requirement of syntheticity. Note that an important point concerning his own notion of analyticity was precisely to show that analytic $\mathrm{F}_{\mathrm{F}}$ propositions can afford valuable extensions of our knowledge; such propositions are thus not analytic $\mathrm{K}_{\mathrm{K}}$. He underlines this for instance explicitly in the case of formula 133, the rather complicated logical proposition which is proved at the end of the Begriffsschrift (cf. Frege 1884, pp. 104-105).

\section{Conclusion}

Kant, Bolzano and Frege conceive of the analytic-synthetic distinction within the framework of the Classical Model of Science. The critical Kant was the first to apply this distinction to propositions or judgments. Bolzano and Frege claimed that their own conceptions of this distinction fit what Kant really should have meant with it. And Kant's analytic ${ }_{K}$ judgments are indeed analytic $_{F}$ and analytic ${ }_{B}$ too. Nevertheless, there are also important differences between these conceptions of analyticity and syntheticity.

Kant connects the analytic-synthetic distinction to the content of propositions while he relates the distinction between a priori and a posteriori judgments to sources of knowledge or ways of justification. Genuine (rational) sciences, like geometry, pure physics or metaphysics (as far as the latter is possible as a science) should be systems of synthetic propositions a priori. Analytic propositions have a very restricted use. They are primarily introduced with regard to the clarification of concepts that especially metaphysics is in need of.

Bolzano, in his project of developing a general theory of science, sticks to the Kantian insight that a real science has to be primarily a system of synthetic propositions. For Bolzano as for Kant, analytic judgments have only a subordinate role in the demonstration of propositions within a science. By restricting a science to the ordo

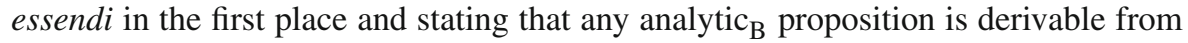
a synthetic ${ }_{\mathrm{B}}$ proposition, Bolzano links the analytic-synthetic distinction to what is called the Universality Postulate. Analytic $\mathrm{B}_{\mathrm{B}}$ propositions are not maximally universal; as such they are not really part of the system of propositions constituting a science (at the level of the ordo essendi).

Kant simply does not apply the analytic-synthetic distinction to (general) logic at all. Although he calls logic a science, (general) logic involves only the formal rules of the understanding. In the tradition of those for whom logic is an ars or instrument and not a science according to the Classical Model of Science, Kant does not conceive of logic as a system of logical, true propositions. However, Bolzano and Frege do, decidedly, conceive of logic as a proper science. In Frege's Begriffsschrift logic seems even to be developed and presented as such for the first time as a formal system according to synthetic method. 
According to Bolzano the proper propositions of logic are synthetic. But he has then to explain how it is possible that Kant's analytic judgments can be proved by logic alone. He does so by his notion of logically analytic ${ }_{B}$ truths, which should be derivable from synthetic ${ }_{B}$ truths of logic. Contrarywise, Frege states, within the framework of his logicist program and relating the analytic-synthetic distinction to sources of knowledge, that logical propositions are analytic F $_{\mathrm{F}}$ (and a priori). Logic is the science of the universal laws of everything which can be thought. In contrast, special sciences like physics and geometry are considered to be synthetic ${ }_{\mathrm{F}}$.

Open Access This article is distributed under the terms of the Creative Commons Attribution Noncommercial License which permits any noncommercial use, distribution, and reproduction in any medium, provided the original author(s) and source are credited.

\section{References}

Berg, J. (1962). Bolzano's logic. Stockholm: Almqvist \& Wiksell.

Buhl, G. (1961). Ableitbarkeit und Abfolge in der Wissenschaftstheorie Bolzanos. Kant-Studien, Ergänzungsheft 83. Köln: Kölner Universitäts-Verlag.

Beth, E. W. (1965). The foundations of mathematics (2nd ed.). Amsterdam: North-Holland Publishing Company.

Bolzano, B. (1837). Wissenschaftslehre. In L. Winter, et al. (Eds.). (1969-). Bernard Bolzano Gesamtausgabe. Reihe 1 (Vols. 11-14). Stuttgart-Bad Canstatt: Frommann-Holzboog. Where possible quotations from J. Berg (Ed.). (1973). Theory of science. B. Terrell (Trans.). Dordrecht: Reidel.

Boswell, T. (1988). On the textual authenticity of Kant's logic. History and Philosophy of Logic, 9, 193-203.

de Jong, W. R. (1995a). How is metaphysics as a science possible? Kant on the distinction between philosophical and mathematical method. The Review of Metaphysics, 49, 235-274.

de Jong, W. R. (1995b). Kant's analytic judgments and the traditional theory of concepts. Journal of the History of Philosophy, 33, 613-641.

de Jong, W. R. (1996). Gottlob Frege and the analytic-synthetic distinction within the framework of the Aristotelian model of science. Kant-Studien, 87, 290-324

de Jong, W. R. (2001). Bernard Bolzano, analyticity and the Aristotelian model of science. Kant-Studien, 92, 328-349.

de Jong, W. R., \& Betti, A. (2008). The classical model of science: A millennia-old model of scientific rationality. Synthese doi:10.1007/s11229-008-9417-4.

Euclid (1956). The Elements. In: T. L. Health (Trans. \& comm.). The thirteen books of The Elements. New York: Dover.

Frege, G. (1879). Begriffsschrift, eine der arithmetischen nachgebildete Formelsprache des reinen Denkens. In I. Angelelli (Ed.). (1971). Begriffsschrift und andere Aufsätze. Hildesheim: Georg Olms.

Frege, G. (1884). Die Grundlagen der Arithmetik. Eine logisch-mathematische Untersuchung über den Begriff der Zahl (1961). Hildesheim: Georg Olms. Quotations from J. L. Austin (Trans.). (1978). The foundations of arithmetic. A logico-mathematical enquiry into the concept of number. Oxford: Blackwell.

Frege, G. (1969). Nachgelassene Schriften. In H. Hermes, et al. (Eds.). Hamburg: Meiner. Quotations from H. Hermes, et al. (Eds.). (1979). Posthumous writings. Chicago: University of Chicago Press.

Frege, G. (1990). Kleine Schriften. In I. Angelelli (Ed.). (2nd ed.). Hildesheim: Georg Olms. Quotations from B. McGuiness (Ed.). (1984). Collected papers on mathematics, logic and philosophy. Oxford: Blackwell.

Hanna, R. (2001). Kant and the foundations of analytic philosophy. Oxford: Clarendon Press.

Kant, I. (1783). Prolegomena zu einer jeden künftigen Metaphysik, die als Wissenschaft wird auftreten können. In Kant (1902), IV, pp. 255-383.

Kant, I. (1787). Kritik der reinen Vernunft (1998). Hamburg: Felix Meiner. References are in the customary way via the pagination of the first $(A)$ or second printing $(B)$.

Kant, I. (1902). Kants gesammelte Schriften. Vol. I-XXIX (1902-1983). Berlin: De Gruyter, Reimer. Quotations from P. Guyer \& A. W. Wood (Eds.). (1992-). The Cambridge edition of the works of Immanuel Kant. Cambridge: Cambridge University Press. 
Kitcher, P. (1979). Frege's epistemology. The Philosophical Review, 88, 235-263.

Leibniz, G. W. (1679). De synthesi et analysi universali seu arte inveniendi et judicandi. In L. E. Loemker (Ed. \& trans.). (1967). Philosophical papers and letters (pp. 229-234). Dordrecht: Reidel.

Proust, J. (1986). Questions de forme. Logique et proposition analytique de Kant à Carnap. Paris: Fayard.

Scholz, H. (1937). Die Wissenschaftslehre Bolzanos. Eine Jahrhundert-Betrachtung. Abhandlungen der Fries'schen Schule (N.F.), 6, 399-472. 